\title{
Polarity Inversion DC-DC Power Conversion Circuit with High Voltage Step-up Ratio
}

\author{
Chung-Wook Roh ${ }^{\dagger}$, Cheol-Hee Yoo*, Dong-Yeol Jung**, Sug-Chin Sakong* \\ $\dagger^{*}$ Dept. of Electrical Engineering, Kookmin University, Seoul, Korea \\ ** IT Solutions Business Imaging Laboratory, Samsung Electronics Company, Suwon, Korea.
}

\begin{abstract}
A novel polarity inversion dc-dc power conversion circuit that features the high input to output step-up voltage conversion ratio characteristics is presented for high voltage DC power supply applications. The proposed circuit features the reduced voltage stresses of the components compared to those of the conventional ones. The operational principles of the proposed circuit are analyzed and comparative features are presented. The simulation results and experimental results are presented to verify the validity of the proposed circuit.
\end{abstract}

Key Words: High Voltage Power Supply, Polarity Inversion, Voltage Multiplier

\section{INTRODUCTION}

High voltage power supply (HVPS) has recently expanded its applications to a variety of industries, and it became an essential part in many areas. Since the applications of HVPS has become so prevalent, they can be found in many different sectors including new composition development and plasma application for industrial, domestic, medical and military uses as well as printers. Printers, which are now a part of everyday life at work and even at home, has adapted high voltage power supply for the Laser Beam Printer (LBP) image processing system.

Fig. 1 shows the conventional polarity inversion DC-DC converter for a HVPS used in the printer application. The conventional circuit, composed of single semiconductor switch, single high-voltage transformer, several diodes and several capacitors, is the well-known flyback converter which employs a voltage multiplier circuit. By incorporating voltage multiplier circuit, the diodes and capacitors with a low stress voltage can be chosen even with a high output voltage above a few $\mathrm{KV}$. Because of its simple structure, it has been widely used for HVPS with a low power capacity in Watt such as printer application. It is noted that in such a printer application, a high negative output voltage with respect to the earth-ground (so called, cold-ground) level is required. The ground levels of

input voltage $\left(V_{i n}\right)$ and the output voltage $\left(-V_{o}\right)$ should be tied to meet the safety requirement.

However, the use of the high-voltage transformer in the

\footnotetext{
Manuscript received Mar. 23, 2010; revised Jul. 22, 2011

Recommended for publication by Associate Editor Jun-Keun Ji.

$\dagger$ Corresponding Author: drno@kookmin.ac.kr

Tel: +82-2-910-4947, Fax: +82-2-910-4449, Kookmin University

* Dept. of Electrical Engineering, Kookmin University, Korea

** IT Solutions Business Imaging Laboratory, Samsung Electronics Company, Korea
}

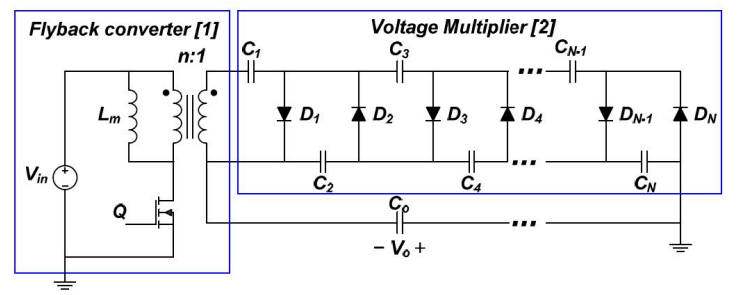

Fig. 1. Polarity Inversion DC-DC converter for conventional high voltage power supply.

conventional circuit requires an increased size of magnetic component, since, there should be an enough spacing between the primary windings and the secondary windings, to prevent a voltage-arch due to high output voltage above one $\mathrm{kV}$. Therefore, it results in a large-window-area transformer. Also, the energy stored in the leakage inductance of the transformer is dissipated in the circuit, which results in a low power conversion efficiency. The high voltage stresses of the diodes and capacitors in the voltage multiplier results in the highprice components. These features have been a major obstacle in minimizing the size and weight of the HVPS and in reducing the cost of whole product [1]-[3].

In this paper, a novel polarity inversion dc-dc power conversion circuit features the reduced voltage stresses of the components and the increased input-output step-up voltage conversion ratio characteristics compared to the conventional one. Instead of using a transformer, the proposed circuit utilizes magnetic components as an inductor. This results in reducing the size of magnetic components while maximizing the efficiency of power conversion. Analysis and the operational principles of the proposed circuit have been done to demonstrate the advantages of the proposed circuit. Simulation and experiment has been performed to verify the validity of 


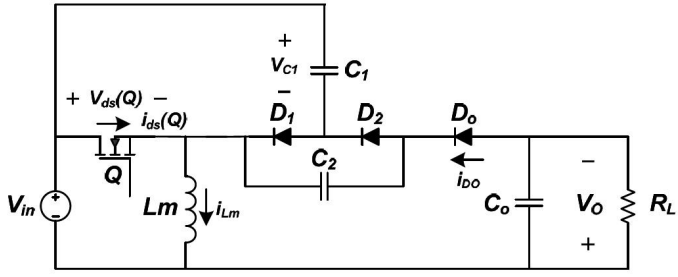

Fig. 2. The proposed Polarity Inversion DC-DC converter of Two-Level.

the proposed circuit.

\section{Operational Principles}

The circuit diagram of the proposed two-level polarity inversion circuit is shown in Fig. 2. The proposed circuit is similar to the conventional polarity inversion circuit in that both of them are composed of Switch $Q$, Inductor $L_{m}$, Diode $D_{O}$ and Capacitor $C_{O}$, while it has an additional voltage multicell, consisting of Diodes $D_{1}$ and $D_{2}$ and Capacitors $C_{1}$ and $C_{2}$, to reduce the component voltage stresses. To analyze the operation of the proposed circuit, the following assumptions have been made.

All power semiconductors are ideal.

The circuit operates in a steady state.

The Capacitor $C_{1}, C_{2}$, and $C_{O}$ are assumed to be large enough so that the voltage across the capacitors are approximated by a DC voltage of the source.

The voltages across the Capacitor $C_{1}$ and $C_{2}$ have a value equal to $V_{X}$.

$V_{\text {in }}<V_{x}<V_{o}$

The last two assumptions become evident from the circuit behavior that is described below in detail.

\section{A. Continuous Conduction Mode(CCM) Operations}

Fig. 3 shows two topological states of the equivalent circuit when the inductor current of the proposed circuit operates in CCM. Key waveforms of the voltage/current for the proposed circuit are illustrated in Fig. 4. The detailed description of each topological state is given in the next.

- Mode $1\left[T_{0} \sim T_{1}\right]$

Mode 1 begins as switch $Q$ is turned off at $T_{0}$. The Diode $D_{1}$ and the output diode $D_{O}$ are forward-biased, and the energy stored in the magnetizing inductance is discharged via paths $L_{m}-V_{i n}-C_{1}-D_{1}$ and $L_{m}-C_{O}-D_{O}-C_{2}$. Therefore, the current $i_{L m}(t)$ flowing through Inductor $L_{m}$ is expressed as follows.

$$
\begin{aligned}
i_{L m}(t) & =i_{L m}\left(T_{0}\right)+\frac{V_{i n}-V_{x}}{L}\left(t-T_{0}\right) \\
& =i_{L m}\left(T_{0}\right)+\frac{V_{x}-V_{o}}{L}\left(t-T_{0}\right) .
\end{aligned}
$$

At $T_{1}$, the current $i_{L m}\left(T_{1}\right)$ can be written as follows.

$$
i_{L m}\left(T_{1}\right)=i_{L m}\left(T_{0}\right)+\frac{V_{x}-V_{o}}{L}(1-D) T_{s}
$$

where $D$ is a duty ratio of the switch $Q$ and $T_{S}$ denotes a switching period. During Mode 1 , the reverse voltage of the diode $D_{2}, V_{D 2}$, and the Drain-to-Source voltage of the switch $Q, V_{D S}(Q)$, become $V_{X}$.

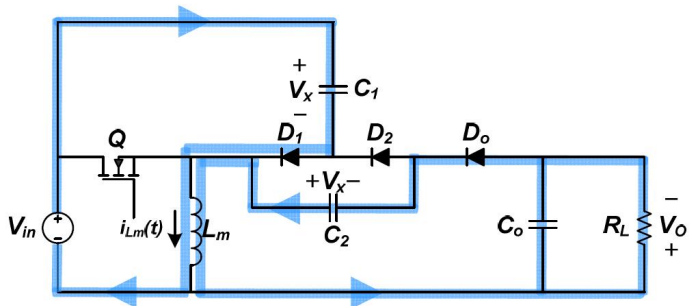

(a) Mode 1: Switch $Q$ off.

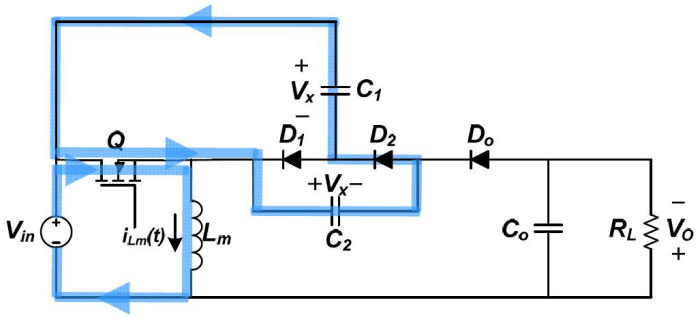

(b) Mode 2: Switch $Q$ on.

Fig. 3. Equivalent Circuit of continuous conduction mode.

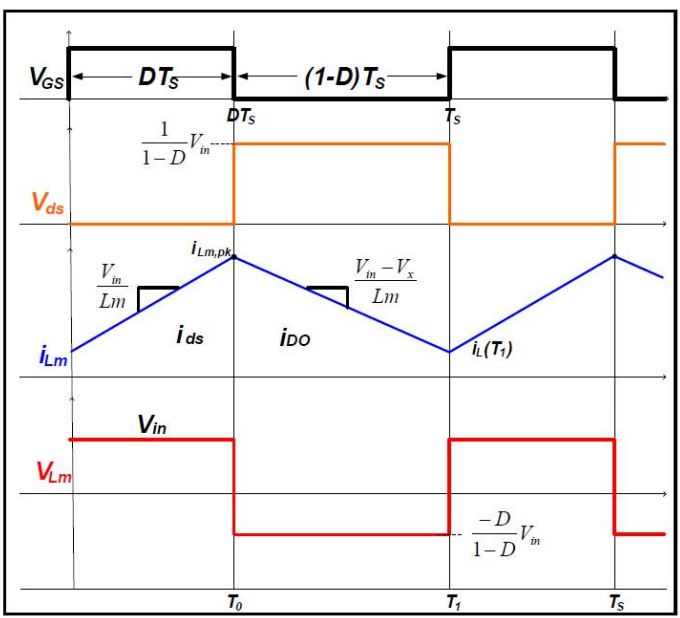

Fig. 4. Steady-state waveforms of CCM.

- Mode $2\left[T_{1} \sim T_{2}\right]$

At $T_{1}$, as the switch $Q$ is turned on, the diodes $D_{1}$ and $D_{O}$ are turned off. Since, during Mode1, capacitor $C_{1}$ is charged and $C_{2}$ is discharged, which results in forward-biased of the diode $D_{2}$ at $T_{2}$. Energy is stored in the magnetizing inductance via the path $V_{i n}-Q-L_{m}$. Therefore, the Inductor Current $i_{L m}(t)$ is expressed as

$$
i_{L m}(t)=i_{L m}\left(T_{1}\right)+\frac{V_{i n}}{L_{m}}\left(t-T_{1}\right) .
$$

At $T_{2}$, the current $i_{L m}\left(T_{2}\right)$ can be written as

$$
i_{L m}\left(T_{2}\right)=i_{L m}\left(T_{1}\right)+\frac{V_{i n}}{L_{m}} D T_{s}=i_{L m}\left(T_{0}\right) .
$$

During Mode 2, the path $C_{1}-Q-C_{2}-D_{2}$ is established, and thus the output voltages $V_{C 1}$ and $V_{C 2}$ across the capacitors $C_{1}$ and $C_{2}$ are equal to $V_{X}$. Therefore, it is obvious that the reverse voltage of the diode $D_{1}, V_{D 1}$, and the reverse voltage of the output diode $D_{O}, V_{D O}$ are equal to $V_{X}$ and $V_{i n}+V_{O}-V_{X}$ , respectively. Mode 2 ends when the switch $Q$ becomes turnoff at $T_{2}$, Mode 1 starts again and the cycle repeats. From the 


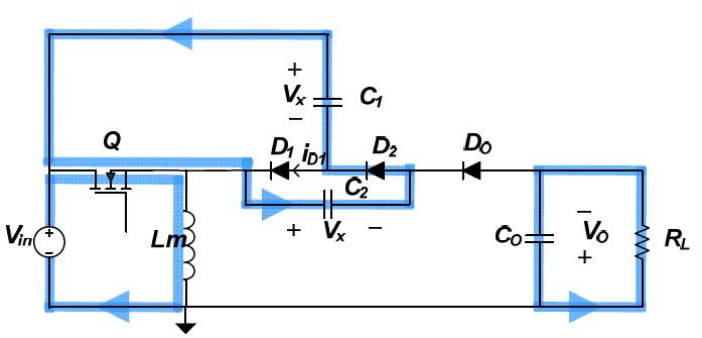

(a) Mode $1:$ Switch $Q$ on.

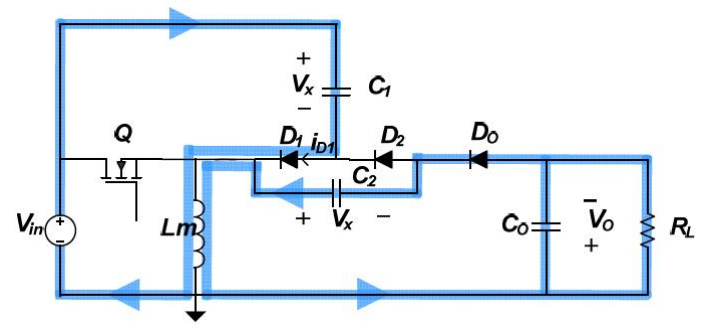

(b) Mode 2 : Switch $Q$ off.

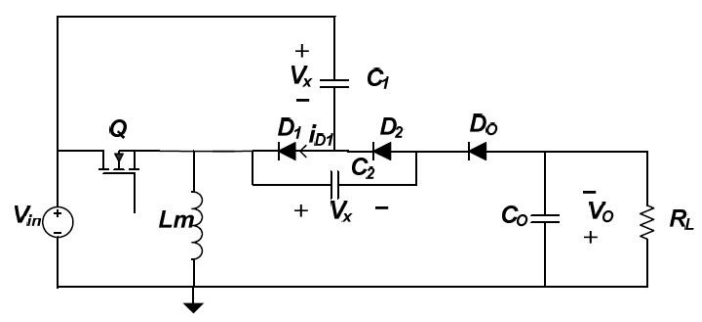

(c) Mode $3:$ Switch $Q$ off and Diode $D_{1}, D_{2}, D_{O}$ off.

Fig. 5. Equivalent Circuit of discontinuous conduction mode.

equations (2) and (3), the voltage across the capacitors $C_{1}$ and $C_{2}, V_{X}$, and the ratio of the input voltage to the output voltage, $V_{O} / V_{\text {in }}$, are given by:

$$
\begin{aligned}
V_{x} & =\frac{V_{i n}}{1-D} \\
\frac{V_{o}}{V_{i n}} & =\frac{1+D}{1-D} .
\end{aligned}
$$

It should be noted that $V_{i n}<V_{X}<V_{O}$ is always true, since the duty ratio $D$ has a value between 0 and 1 .

\section{B. Discontinuous Conduction Mode(DCM) Operations}

Fig. 5 shows three topological states of the equivalent circuit when the inductor current $i_{L m}(t)$ of the proposed circuit operates in DCM, and Fig. 6 illustrates key waveforms of the voltage/current for the proposed circuit. The three operational modes are briefly described as follows:

- Mode 1[ $\left.T_{0} \sim T_{1}\right]$

When the switch $Q$ is turned on at $T_{0}$, diodes $D_{1}$ and $D_{O}$ are reversed-biased, and diode $D_{2}$ starts to conduct. Energy is stored in the magnetizing inductance $L_{m}$ via the path $V_{i n}-Q$ $-L_{m}$. Therefore, the current $i_{L m}(t)$ flowing through Inductor $L_{m}$ is expressed as

$$
i_{L m}(t)=\frac{V_{i n}}{L_{m}}\left(t-T_{0}\right)
$$

At $T_{0}$, current $i_{L m}\left(T_{1}\right)$ can be written as

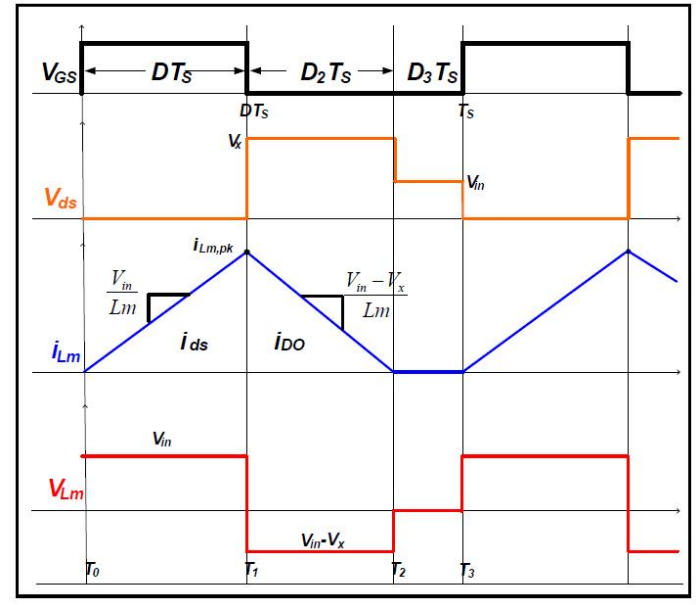

Fig. 6. Steady-state waveforms of DCM.

$$
i_{L m}\left(T_{1}\right)=\frac{V_{\text {in }}}{L_{m}} D T_{s}
$$

During Mode 1 , as the diode $D_{2}$ is turned on, the path $C_{1}$ $Q-C_{2}-D_{2}$ is established and thus the voltage $V_{C 1}$ and $V_{C 2}$ across the capacitors $C_{1}$ and $C_{2}$ are equal to the voltage $V_{X}$. The reverse voltage of diode $D_{1}, V_{D 1}$, and the reverse voltage of output diode $D_{O}, V_{D O}$ are equal to $V_{X}$ and $V_{i n}+V_{O}-V_{X}$, respectively.

- Mode $2\left[T_{1} \sim T_{2}\right]$

When the switch $Q$ is turned off at $T_{1}$, the diode $D_{1}$ and the output diode $D_{O}$ are forward-biased, and the energy stored in the magnetizing inductance is discharged via the paths $L_{m}-$ $V_{i n}-C_{1}-D_{1}$ and $L_{m}-C_{O}-D_{O}-C_{2}$. Therefore, the current $i_{L m}\left(T_{1}\right)$ flowing through Inductor is expressed as

$$
\begin{aligned}
i_{L m}(t) & =i_{L m}\left(T_{1}\right)+\frac{V_{i n}-V_{x}}{L_{m}}\left(t-T_{1}\right) \\
& =i_{L m}\left(T_{1}\right)+\frac{V_{x}-V_{o}}{L_{m}}\left(t-T_{1}\right) .
\end{aligned}
$$

In Mode 2, the reverse voltage $V_{D 2}$ of diode $D_{2}$ and Drainto-source voltage $V_{D S}(Q)$ of switch $Q$ follow the voltage $V_{X}$.

At $T_{2}$, inductor current $i_{L m}\left(T_{2}\right)$ is reduced to Zero and the following equation can be derived from the equations (8) and (9): Using Eq. (8), (9), Eq. (10) can be expressed as

$$
D V_{\text {in }}=D_{2}\left(V_{x}-V_{\text {in }}\right)=D_{2}\left(V_{o}-V_{x}\right)
$$

Where $D_{2}=\left(T_{2}-T_{1}\right) / T_{S}$.

- Mode $3\left[T_{2} \sim T_{3}\right]$

At $T_{2}$, all the diodes are turned off, and the voltage across the inductor and the current flowing through the inductor are reduced to 0 . During Mode 3 , the voltages $V_{D S}(Q)$, $V_{D O}, V_{D 1}$ and $V_{D 2}$ are equal to $V_{i n}, V_{O^{-}} V_{X}, V_{X}-V_{i n}$ and $V_{i n}$, respectively. When the switch $Q$ is turned on at $T_{3}$, Mode 1 starts again and the cycle repeats.

The voltage $V_{X}$ across the capacitors $C_{1}$ and $C_{2}$ and the input to output voltage ratio $V_{O} / V_{\text {in }}$ can be derived from equation (10) and expressed as follow.

$$
V_{x}=\frac{D+D_{2}}{D_{2}} V_{i n}
$$




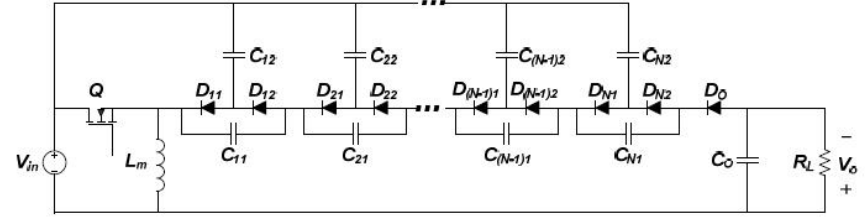

Fig. 7. Polarity Inversion DC-DC converter of N-Level.

$$
V_{o}=\frac{2 \cdot D+D_{2}}{D_{2}} V_{i n} .
$$

As shown in Fig. 6, the output load current $I_{O}$ is an average of the output diode current $I_{D O}$, and satisfies the following.

$$
I_{o}=\frac{V_{O}}{R_{L}}=\frac{D_{2} \cdot i_{L m}\left(T_{1}\right)}{4} .
$$

When equations (8) and (13) are combined, $D_{2}$ is given by

$$
D_{2}=\frac{2 K}{D} \cdot \frac{V_{o}}{V_{\text {in }}} .
$$

where, $K=L_{m} /\left(R_{L} T_{S}\right)$.

When equations (12) and (14) are combined, the input to output voltage ratio $V_{O} / V_{\text {in }}$ of the proposed circuit operating in DCM is given by

$$
\frac{V_{o}}{V_{i n}}=\frac{1+\sqrt{1+\frac{4 D^{2}}{K}}}{2} .
$$

Equation (15) shows that high output voltage gain is obtained by $L_{m}, R_{L}, T_{S}$.

\section{N-Level Polarity Inversion DC-DC converter}

Fig. 7 illustrates the proposed DC-DC converter with Nlevel polarity inversion. The circuit basically expands the concept of the two-level polarity inversion circuit, and, reduction in the component stress increases as the number of level increases. When the switch $Q$ is turned on, the N-level DCDC converter stores energy in the inductor $L_{m}$, and diodes $D_{12}, D_{22}, \ldots, D_{(N-1) 2}, D_{N 2}$ are turned on, which leads to the voltage balance among the capacitors. When the switch $Q$ is turned off, the output diode $D_{O}$ and diodes $D_{11}, D_{21}$, $\ldots, D_{(N-1) 1}, D_{N 1}$ are turned on, and thus the energy stored in the inductor is supplied to the output load. The following equations can be obtained by applying the same process of analysis employed for the operational principles of the proposed DC-DC converter with two-level polarity inversion. In $\mathrm{CCM}$ operation, the input to output voltage ratio is given by

$$
\left.\frac{V_{o}}{V_{\text {in }}}\right|_{C C M}=\frac{N-1}{1-D}+\frac{D}{1-D} .
$$

In DCM operation, the input to output voltage ratio is given by

$$
\left.\frac{V_{o}}{V_{i n}}\right|_{D C M}=\frac{N-1+\sqrt{(N-1)^{2}+4 D^{2} / K}}{2}
$$

where $K=L_{m} /\left(R_{L} T_{S}\right)$.

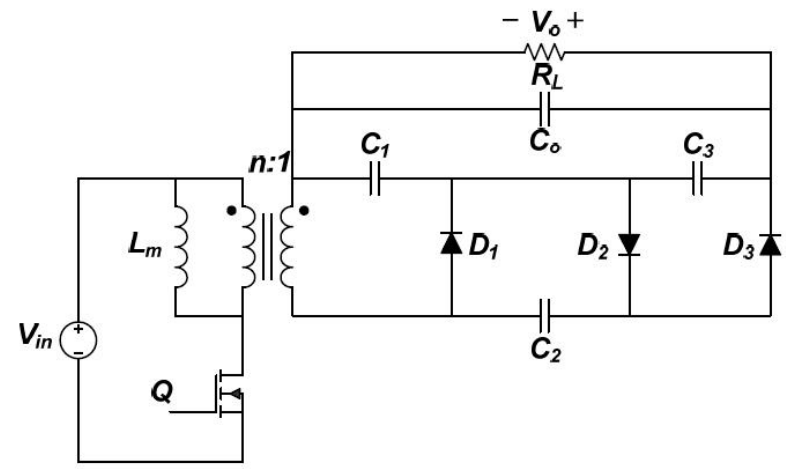

(a) The flyback converter using triple voltage Multipliers.

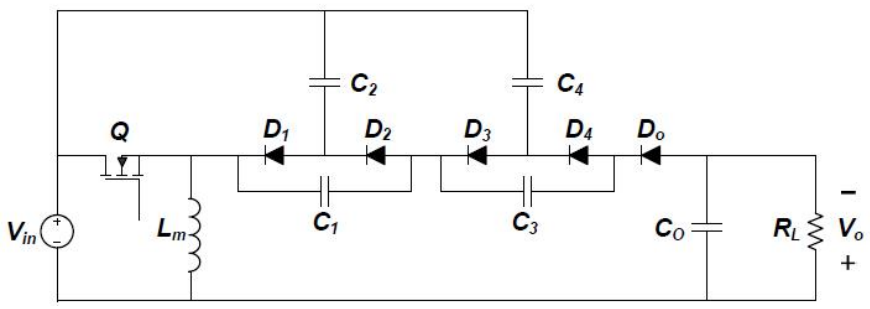

(b) Polarity Inversion DC-DC converter of 3-Level.

Fig. 8. Comparison of the circuits.

\section{COMPARISON TO THE CONVENTIONAL CiRCUIT}

A. Polarity inversion DC-DC converter with 3-Level VS. Flyback converter using triple voltage multipliers

Compared to the conventional circuit with a voltage multiplier, the proposed polarity inversion DC-DC converter features the low voltage stresses of the components, which save the cost and volume. To prove the hypothesis, we compared the proposed DC-DC converter with 3-level polarity inversion and the flyback converter with triple voltage multiplier.

Fig. 8(a) demonstrates the flyback converter using triple voltage multiplier, where the transformer turns ratio is assumed to be 1 . The conventional circuit contains four less diodes compared to the proposed circuit shown in Fig. 8(b). Although the proposed circuit consists of a greater number of components, the cost of the power converter can be actually reduced since the voltage stresses of the proposed circuit are lower than those of the conventional one. Table I shows the voltage stresses comparison of the components for each circuit. As can be seen, the duty ratio of the proposed circuit is smaller than that of the conventional one under the same input-output voltage condition. In consequence, the voltage stresses for all components in the proposed circuit, except the capacitor $C_{4}$, remains low.

The component stresses of the conventional circuit compared to the proposal circuit versus the input-output voltage conversion ratio $M$, is shown in Fig. 9. The voltage stresses of all elements except $C_{4}$ decreases in the proposed circuit as $M$ increases. Thus, the proposed circuit is well suited in the high step-up voltage conversion application such as HVPS in LBP. It is noted that if the turns ratio of transformer in the conventional circuit is set to $\mathrm{n}$, larger than one, the maximum reverse voltage of diode $\left(D_{1}, D_{2}, D_{3}\right)$ and the voltage of capacitor $\left(C_{1}, C_{2}, C_{3}\right)$ will increase more. Even 


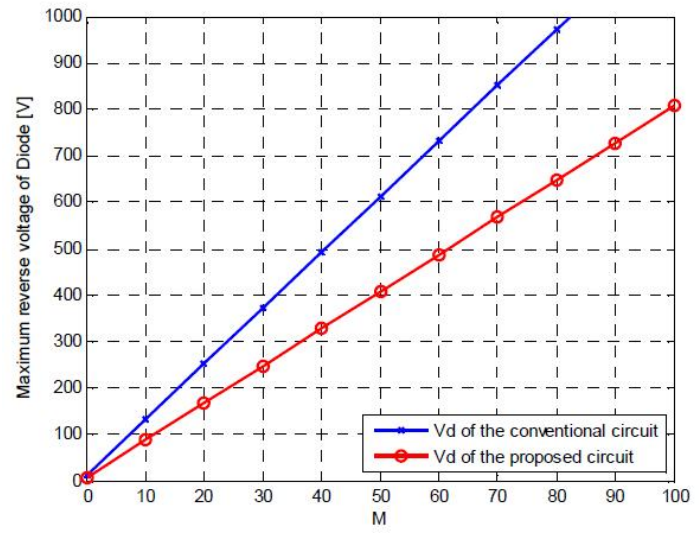

(a) Maximum reverse vtg. of diode.

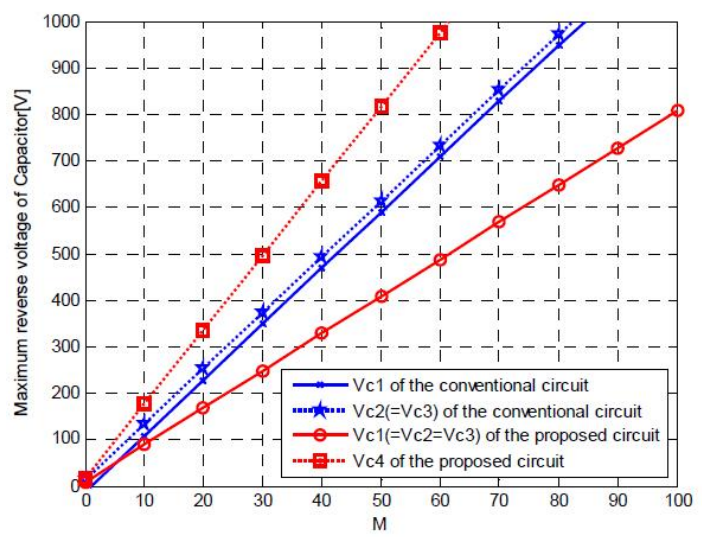

(b) Maximum reverse vtg. of Capacitor.

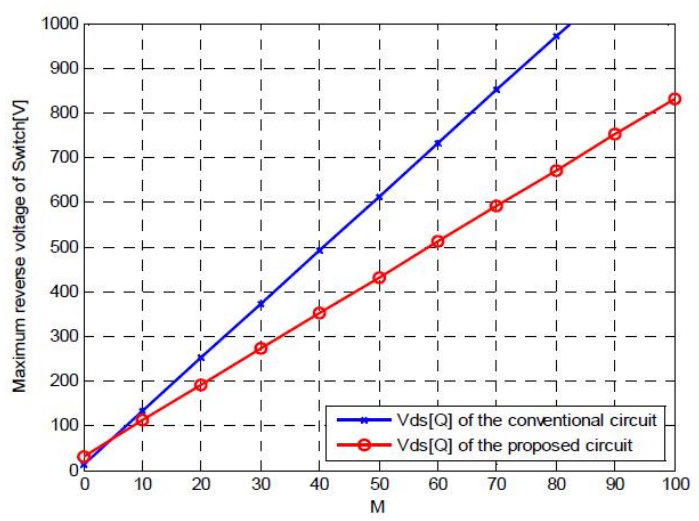

(c) Maximum reverse vtg. Of Switch.

Fig. 9. The proposed Polarity Inversion DC-DC converter of Two-Level.

when considering turns ratio of the transformer, it is expected that the proposed circuit is superior to the conventional one.

\section{B. Design Considerations and Design example}

For comparison, the specifications used in a typical HVPS in LBP are listed as follows :

Input voltage $V_{D C}: 24 \mathrm{~V}_{D C}$

Output voltage $V_{O}:-1200 \mathrm{~V}_{D C}$

Output power $P_{O}: 15 \mathrm{~W}$

Switching frequency $\mathrm{f}_{S}: 50 \mathrm{kHz}$

Inductor current operation mode : Continuous conduction mode $(\mathrm{CCM})$

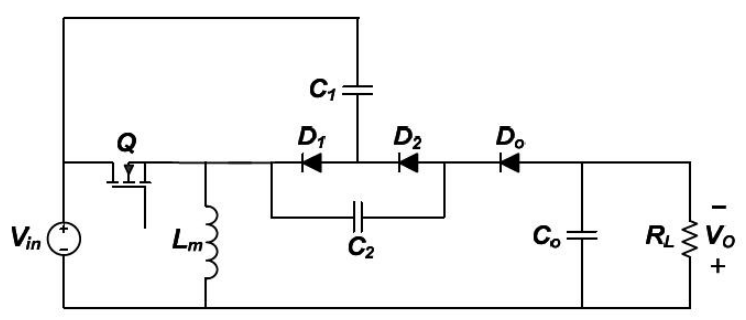

(a) Polarity Inversion DC-DC converter of 2-Level.

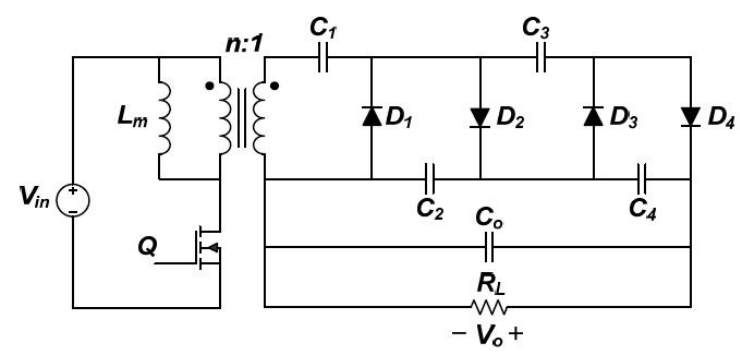

(b) The flyback converter using quadruple voltage Multipliers.

Fig. 10. Comparison of the circuits.

\section{- Duty ratio}

The required input output voltage ratio $\left(V_{O} / V_{i n}\right)$ is 50 . As shown in Table I, the duty ratio D of the proposed DC-DC converter is 0.9410 , while the duty ratio $\mathrm{D}^{*}$ of the flyback converter using triple voltage multipliers is 0.9607 .

\section{- Switch}

The maximum drain-to-source voltage of the switch $V_{D S}(Q)$ is $432 \mathrm{~V}$, and that of the conventional circuit $V_{D S} *(Q)$ is $612 \mathrm{~V}$.

\section{- Diode}

Diodes should be selected to have the standard capacity greater than the maximum reverse voltage. The maximum reverse voltages of all diodes are $408 \mathrm{~V}$ for the proposed circuit, while those are $612 \mathrm{~V}$ for the flyback converter using triple voltage multiplier (Table I).

\section{- Capacitor}

Capacitors should have a greater capacity than the maximum stress voltage, considering the de-rating factor. As shown in Table I, the maximum capacitor voltages of $C_{1}, C_{2}$ and $C_{3}$ are the same values of $408 \mathrm{~V}$, and that of $C_{4}$ is $816 \mathrm{~V}$, in the proposed circuit. On the other hand, in the conventional circuit, the voltages across $C_{1}, C_{2}$ and $C_{3}$ are $588 \mathrm{~V}, 612 \mathrm{~V}$ and $612 \mathrm{~V}$, respectively.

In this design example, it seems that the proposed circuit successfully reduces the voltage stress for its components by at least $30 \%$, compared to the conventional one. Therefore, the proposed circuit has an advantage in design which enables the use of low-cost and low-rating components, resulting in a significant cost reduction in the production of high voltage power supply.

$\cdot n$ : transformer turns ratio

- $M$ : input-output voltage ratio

- $D$ : Proposed circuit Duty ratio

- $D^{*}$ : Conventional circuit Duty ratio

- Conventional circuit : The flyback converter using triple voltage Multipliers

- Proposed circuit : Polarity Inversion DC-DC converter of 3-Level 
TABLE I

COMPARISON OF THE COMPONENT STRESSES AND SIZE

\begin{tabular}{|c|c|c|}
\hline Item & Conventional circuit & Proposed circuit \\
\hline$n$ & $n=\frac{\text { turns of primary side }}{\text { turns of secondary side }}$ & - \\
\hline$M$ & $M=\frac{1}{n} \cdot \frac{1+D^{*}}{1-D^{*}}$ & $M=\frac{2+D}{1-D}$ \\
\hline$D$ & $D^{*}=\frac{n M-1}{n M+1}$ & $D=\frac{M-2}{M+1}$ \\
\hline $\begin{array}{l}\text { Diode Max. } \\
\text { reverse Vtg. }\end{array}$ & $\begin{array}{l}V_{D 1}=V_{D 2} \\
=V_{D 3}=\frac{1}{n} \cdot \frac{V_{i n}}{1-D^{*}}\end{array}$ & $\begin{array}{l}V_{D 1}=V_{D 2}=V_{D 3} \\
=V_{D 4}=V_{D o}=\frac{V_{i n}}{1-D}\end{array}$ \\
\hline $\begin{array}{l}\text { Capacitor } \\
\text { Vtg. }\end{array}$ & $\begin{array}{l}V_{C 1}=\frac{1}{n} \cdot \frac{D^{*}}{1-D^{*}} V_{i n} \\
V_{C 2}=V_{C 3}=\frac{1}{n} \cdot \frac{1}{1-D^{*}} V_{i n}\end{array}$ & $\begin{array}{l}V_{C 1}=V_{C 2}=V_{C 3}=\frac{V_{i n}}{1-D} \\
V_{C 4}=\frac{2 V_{i n}}{1-D}\end{array}$ \\
\hline $\begin{array}{l}\text { Switch Q } \\
\text { Max. Vtg. }\end{array}$ & $V_{d s}=V_{i n}+\frac{D^{*}}{1-D^{*}} V_{i n}$ & $V_{d s}=V_{i n}+\frac{1}{1-D} V_{i n}$ \\
\hline $\begin{array}{l}\text { Core size of } \\
\text { magnetic } \\
\text { components } \\
\text { (Volume) }\end{array}$ & $\begin{array}{l}\text { EE2525S } \\
\quad\left(2760 \mathrm{~mm}^{2}\right)\end{array}$ & $\begin{array}{l}\text { EE2519S } \\
\left(1940 \mathrm{~mm}^{2}\right)\end{array}$ \\
\hline
\end{tabular}

C. Polarity Inversion DC-DC converter with 2-Level VS. Flyback converter using quadruple voltage multipliers

Even if the proposed converter is designed with the same voltage stresses of the components as those used in the conventional converter, the effect of the cost reduction can still be achieved since the number of the components is reduced compared to the conventional one in designing the HVPS. Under the specifications in the previous design example, we also compared the proposed circuit with two-level polarity inversion and the flyback converter with quadruple voltage multipliers. The proposed and flyback converters are shown in Fig. 10.

\section{- Duty ratio}

The duty ratio is 0.9608 for the proposed DC-DC converter with two-level polarity inversion, and 0.9600 for the conventional flyback converter.

\section{- Switch}

The maximum drain to source voltage $V_{D S} *(Q)$ and the maximum current $I_{D S, p k}$ of the switch are $636 \mathrm{~V}$ and $1.275 \mathrm{~A}$, in the proposed circuit, while those are $612 \mathrm{~V}$ and $1.29 \mathrm{~A}$, in the conventional circuit, respectively. When considering the reliability, the maximum drain-to-source voltage and the maximum current of the switch should be chosen to have greater values than $700 \mathrm{~V}$ and $1.5 \mathrm{~A}$, respectively, for both circuits. In other words, the same power switch component can be selected for both circuits.

\section{- Diode}

The maximum reverse voltages of each diode for the proposed circuit are $612 \mathrm{~V}$, and those are $612 \mathrm{~V}$ for the conventional circuit. Thus, the same diode component can be selected for both circuits.

\section{- Magnetic components}

Instead of using a transformer, the proposed circuit utilizes magnetic components as an inductor. This results in reducing the size of magnetic components. As shown in Table I, the

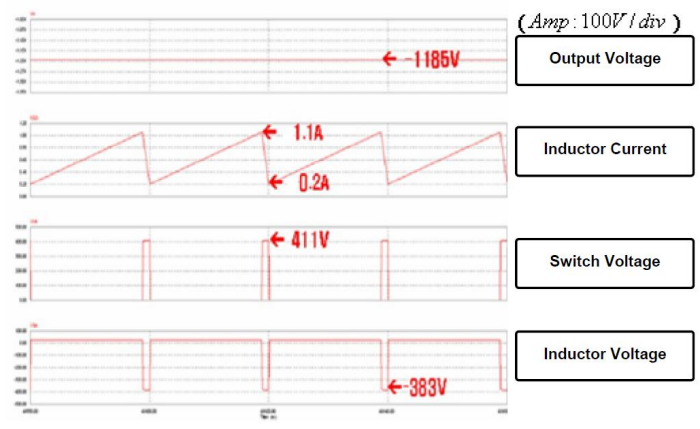

Fig. 11. Simulated Waveforms of the proposed circuit(3-Level circuit).

proposed converter can reduce approximately $30 \%$ in magnetic components.

\section{- Capacitor}

The voltages across the capacitors for the proposed circuit, $C_{1}$ and $C_{2}$ are all $612 \mathrm{~V}$. The voltages $C_{1}, C_{2}, C_{3}$ and $C_{4}$ composing the conventional circuit are $588 \mathrm{~V}, 612 \mathrm{~V}, 612 \mathrm{~V}$ and $612 \mathrm{~V}$, respectively. Except for $\mathrm{C}_{1}$ of the conventional circuit, the capacitors which have the maximum voltage greater than $700 \mathrm{~V}$, should be used for both circuit.

When both converters are compared for their component voltage stresses following the specifications of the design example described above, the similar components should be used. This example clearly demonstrates that the proposed circuit can be built using one less diode and on less capacitor compared to the conventional circuit, resulting in the cost reduction.

\section{Simulation and Experimental Results}

The performance of the proposed converter is verified by PSIM simulation and experimental results. The specifications of the circuit are the same as the previous design example. The proposed converter with 3-Level polarity inversion is implemented with the conditions that the inductance $\mathrm{Lm}$ is $531 \mathrm{uH}$ and the capacitances $C_{1} \sim C_{4}$, including $C_{O}$ are the same value of $33 \mathrm{nF}$.

Fig. 11 shows the simulation results for the proposed circuit with 3-Level. When a 3-level polarity inversion DCDC converter was designed targeting the output voltage of $-1200 \mathrm{~V}$, the simulation result showed the output voltage of $-1185 \mathrm{~V}$. The difference between the target and simulation output voltages was approximately $15 \mathrm{~V}$, falling within the $5 \%$ error range of the simulation. The magnetic inductance current of the proposed Polarity Inversion DC-DC converter with 3Level is operated in CCM. The maximum peak current is 1.1A, and the minimum current is $0.2 \mathrm{~A}$. The drain-source voltage switch measured is $411 \mathrm{~V}$. Inductor voltage is measured $24 \mathrm{~V}$ at the switch ON time. Inductor voltage is measured -383V at the switch OFF time. Simulation results show that all the values and calculated values are within the range of 5\% error of the match.

Fig. 12 shows the experimental results for the proposed Polarity Inversion DC-DC converter of 3-Level. The experimental parameters are equal to the simulation parameters. The experimental waveforms of the output voltage of the converter are given in Fig. 11, which is in good agreement with the 


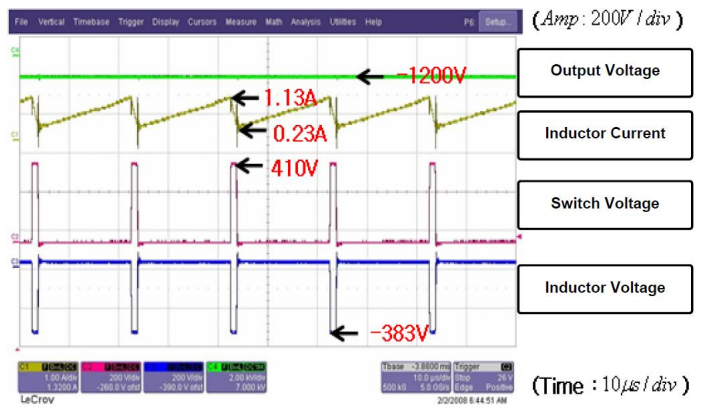

Fig. 12. Measured waveforms of the proposed circuit (3-Level circuit).

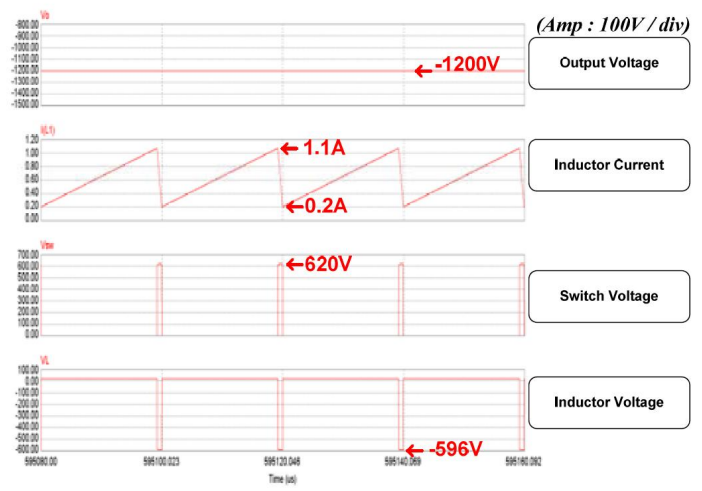

Fig. 13. Simulated Waveforms of the proposed circuit(2-Level circuit).

theoretical estimation. The magnetic inductance current of the proposed Polarity Inversion DC-DC converter with 3-Level is operated in CCM. The maximum current is $1.13 \mathrm{~A}$, and minimum current is $0.23 \mathrm{~A}$. The results are within the margin of error in matching the simulation results. The drain-source voltage of the switch is $410 \mathrm{~V}$. And Inductor voltage is $24 \mathrm{~V}$ at switch ON time, $-383 \mathrm{~V}$ at switch OFF time. Simulation results of the experiment resulting value is a calculated value of all the values match within the margin of error $5 \%$.

Fig. 13 shows the simulation results for the proposed circuit with 2-Level. The results are good agreement with the analysis.

Fig. 14 shows the comparison of the measured efficiency between the conventional converter and proposed converters. As shown in this figure, the proposed converter can achieve higher efficiency along wide load ranges (10-100\%), and its efficiency at the full-load condition (16W) is as high as $87.7 \%$.

\section{CONCLUSIONS}

A novel polarity inversion dc-dc power conversion circuit that has the high input-output voltage conversion ration characteristics is presented for high voltage DC power supply applications. The proposed circuit features the reduced voltage stresses of the component compared to those of the conventional ones. The operational principles of the proposed circuit are analyzed and comparative features are presented. The simple formulas and choosing the parameters of the converter elements are given. The features of this converter include high efficiency, low voltage stress on the switching elements. The computer simulation and experimental results have verified the predictions of the theoretical analysis.

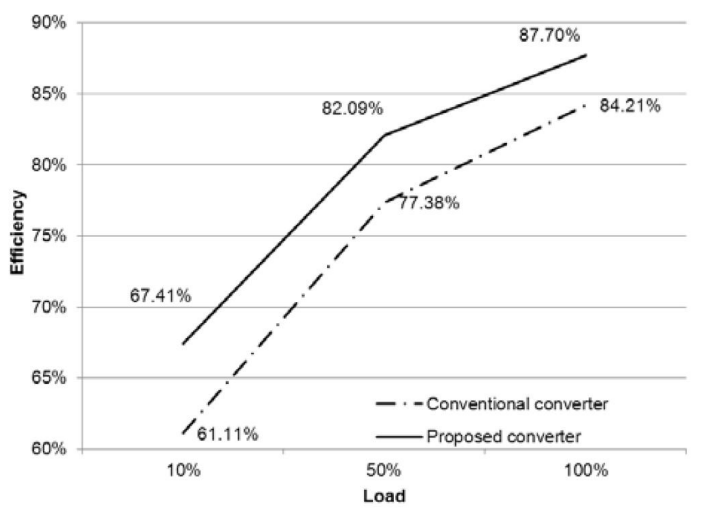

Fig. 14. Comparison of the measured efficiency betweenthe proposed and conventional converters.

\section{ACKNOWLEDGMENT}

This work was supported by the research program 2011 of Kookmin University, Korea and also supported by the Ministry of Knowledge Economy(MKE), Korea, under the Information Technology Research Center(ITRC) support program supervised by the Institute of Information Technology Advancement(IITA) under Grant IITA - 2009 - C1090 - 0904 - 0002 .

\section{REFERENCES}

[1] K. H. Billings, Switchmode Power Supply Handbook, 2nd ed., Chap. 3, pp. 64-107, McGraw-Hill, 1999.

[2] Q. Zhao and F. C. Lee, "High performance coupled-inductor DC-DC converters," in IEEE-APEC Proc., 2003.

[3] L. Hurber and M. M. Jovanovic, "A design approach for server power supplies for networking," in proc. IEEE-APEC, Vol. 2, pp. 1163-1169, 2000.

[4] N. Kasa and T. Lida, "A Transformer-less single phase inverter using a buck-boost type chopper circuit for photovoltaic power system," Proceedings of ICPE'98, Seoul, pp.978-981, 1998.

[5] M. H. Rashid, Power Electronics Circuits, Devices, And Applications, Chap.3, pp 37-88, Prentice-Hall, 1995.

[6] J. D. Cockroft and E.T.S. Walton, Further Development On The Method Of Obtaining High Velocity Positive Ions, Proc. Royal Society London, UK, 1932.

[7] B. Singh and G. D. Chaturvedi, "Analysis, design and development of a single switch flyback buck-boost AC-DC converter for low power battery charging applications," Journal of Power Electronics, Vol. 7, No.4, Oct. 2007.

[8] S.-S. Hong, S.-K. Ji, Y.-J. Jung, and C.-W. Roh, "Analysis and design of a high voltage flyback converter with resonant elements," Journal of Power Electronics, Vol. 10, No. 2, Mar. 2010.

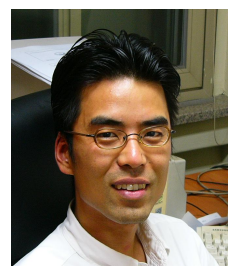

Chung-Wook Roh was born in Korea in 1971. He received the B.S., M.S., and Ph.D. degrees in electrical engineering and computer science from Korea Advanced Institute of Science and Technology (KAIST), Taejon, Korea, in 1993, 1995, and 2000, respectively. In 2000, he joined the Digital Media Network Division, Samsung Electronics Company, Suwon, Korea, where he was a Project Leader of the Plasma Display Driver Development Team. Since 2004, he has been with the department of Electrical Engineering, Kookmin University, where he is currently an Associate Professor. at Kookmin University, Seoul, Korea. His research interests include driver circuits of display such as light emitting diode, plasma display panels, low-power circuits for flat panel displays, modeling, design, and control of power conversion circuits, soft-switching power converters, resonant inverters, and electric drive systems. He is the author or coauthor of more than 100 technical papers published in journals and conference proceedings and has more than 50 patents. Dr. Roh has received several awards including a Best Presentation Award from the annual conference of the IEEE Industrial Electronics Society in 2002, a Best Paper 
Award from the Korean Institute of Power Electronics in 2003, a Best Paper Award from the Korean Institute of Power Electronics in 2009, respectively. $\mathrm{He}$ is currently a journal editor of he Korean Institute of Power Electronics.

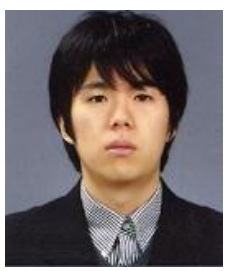

Cheol-Hee Yoo was born in Seoul, Korea in 1982 $\mathrm{He}$ received the B.S. and M.S. degrees in electronics engineering from Kookmin University, CitySeoul, Korea, in 2007, 2009, respectively, where he is currently working toward his Ph.D. in the School of Electronics Engineering. His research interests are in the areas of high-efficiency power converters, renewable energy applications. Mr. Yoo is a member of $\operatorname{KIPE}$ (Korean Institute of Power Electronics).

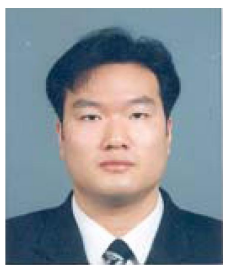

Dong-Yeol Jung was born in Seoul, Korea in 1974. He received his B.S in Electronics Engineering from Suwon University, Suwon, Korea, in 1998. He received his M.S. and $\mathrm{Ph} . \mathrm{D}$. in Electronics Engineering from Kookmin University, Seoul, Korea, in 1998 and 2008. From 2003 to 2005, he was a Research Engineer at Hyundai Autonet Co., Ltd., where he worked on car audio and navigation system. Since 2005 , he has been with the IT Solutions Business Imaging Laboratory, Samsung Electronics Company, Suwon, Korea. His research interests include Power converter modeling, high speed interface signal integrity, power integrity, Power Delivery Network(PDN), SoC Package Modeling, electrical computer aided engineering, EMC Analysis.

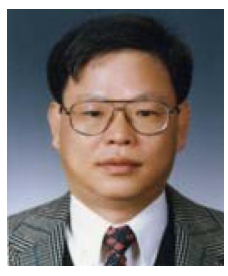

Sug-Chin Sakong received the M.S. and Ph.D. degrees in electrical engineering from Korea University, Seoul, Korea, in 1980 and 1985, respectively. From 1990 to 1991, he was an Invited Professor in the Department of Electronic Engineering, ETH, Switzerland. From 1994 to 1996 he was a Member of the Evaluation Committee of the SMPS Practical Technology Department, Korean National Institute Technology and Quality. Since 1998, he has been a Director with the Korean Institute of Communication Sciences. In 1982, he joined the Electronics Engineering Department, Kookmin University, Seoul, Korea, where he is presently a Professor. His research interests are in the areas of digital communications, and modeling and control techniques for power converters. 